\title{
The Interleukin-1 Receptor-Associated Kinase M Selectively Inhibits the Alternative, Instead of the Classical NFkB Pathway
}

\author{
Jianmin Su Tongli Zhang John Tyson Liwu Li \\ Department of Biological Sciences, Virginia Polytechnic Institute and State University, Blacksburg, Va., USA
}

\section{Key Words}

Alternative pathway · Computational simulation $\cdot$ IRAK-M • $\mathrm{NF} \mathrm{K} \cdot$ Innate immunity $\cdot$ Signaling

\begin{abstract}
The innate immunity signaling process is controlled by numerous positive and negative regulators. The interleukin-1 receptor-associated kinase $M$ (IRAK-M) is one of the negative regulators that contribute to the attenuation of $\mathrm{NF \kappa B}$ activation. The molecular mechanism involved, however, is poorly defined. In this report, we observed that IRAK-M selectively suppresses the NIK-IKK $\alpha$-mediated alternative NFKB pathway. Deletion of IRAK-M led to NIK stabilization, favored the formation of the IKK $\alpha / I K K \alpha$ homodimer instead of the IKK $\alpha /$ IKK $\beta$ heterodimer, and enhanced RelB nuclear distribution. In contrast, p65 nuclear localization and phosphorylation was not affected by IRAK-M deficiency. IRAK-M-deficient cells exhibited increased expression of selected cytokines such as IL- 6 and GM-CSF, as well as quickened resynthesis of $I \kappa B \alpha$. The increased expression of IL- 6 and GM-CSF was ablated when RelB expression was knocked down using specific siRNA. We also demonstrated that the observed inhibitory effect of IRAK-M was primarily limited to the TLR2 ligand, instead of TLR4. Taken together, our findings suggest that IRAK-M negatively regulates the alternative NFKB pathway in a ligand-specific manner.

Copyright @ 2008 S. Karger AG, Basel
\end{abstract}

\section{Introduction}

The Toll-like-receptor (TLR)-mediated signaling pathway is essential for the regulation of the innate immunity signaling process. The TLR signaling pathway often leads to the activation of the NFкB family transcription factors. NFкB family members (p65/RelA, c-Rel, RelB, p100/p52, p105/p50, inhibitory IкB- $\alpha,-\beta,-\varepsilon$, and $-\zeta$, and BCL3) are pivotal for the expression of immunity genes, regulation of apoptosis, cancer biology, and development $[1,2]$. There are multiple pathways that can lead to differential NFKB activation. The classical (canonical) pathway involves the activation of IKK $\alpha / \beta$ by TAK 1 , subsequent phosphorylation and degradation of $\mathrm{I} \kappa \mathrm{B} \alpha$, and release of p65/p50 from the cytoplasm into the nucleus [3]. The classical pathway is responsible for the induction of numerous cytokines and chemokines. The majority of studies regarding TLR signaling have focused on defining the role and regulation of the classical $N F \kappa B$ pathway. The ligation of TLRs has been shown to lead to the recruitment of MyD88, TRAF6, and subsequent activation of TAK1 mediated by TAB1/2 [4]. On the other hand, the alternative (non-canonical) $\mathrm{NF \kappa B}$ pathway involves NFкB-inducing kinase (NIK)-mediated IKK $\alpha$-dependent p100 cleavage and nuclear translocation of RelB/p52. The alternative pathway is thought to be limited to the engagement of lymphotoxin $\beta$ receptor (LT $\beta R$ ), a B-cellactivating factor belonging to the TNF family (BAFF) receptor (BAFF-R) or CD40 [5]. The activation of the alternative pathway has been linked with the maturation of

\section{KARGER}

Fax +4161306 1234

E-Mail karger@karger.ch

www.karger.com
(C) 2008 S. Karger AG, Basel

Accessible online at: www.karger.com/jin
Dr. Liwu Li

Department of Biological Sciences

Virginia Polytechnic Institute and State University

Life Science 1 Building, Washington Street, Blacksburg, VA 24061 (USA)

Tel. +1 540231 1433, Fax +1 540231 4043, E-Mail lwli@vt.edu 
antigen-presenting cells and the development of lymphoid organs. Recently, the alternative pathway has attracted attention due to its significance in regulating various inflammatory processes [6].

IRAK-M was initially cloned as a homologue of IRAK1 [7]. Earlier studies employing transient overexpression of IRAK-M revealed that IRAK-M may activate NFKB reporter activity [7]. Strikingly, later studies using IRAK$\mathrm{M}^{-/-}$cells indicate otherwise. IRAK-M ${ }^{-/-}$macrophages exhibit enhanced NFKB activity and elevated expression of various inflammatory cytokines upon stimulation with several TLR ligands, indicating that IRAK-M may actually inhibit NFKB activation [8]. We have generated data indicating that IRAK-M selectively attenuates TLR2ligand-mediated p38 activation [9]. Phenotypically, IRAK-M $^{-/-}$mice develop severe osteoporosis [10]. In a recent study in humans, genetic variations in the IRAK$\mathrm{M}$ gene are highly correlated with the risk of acute asthma [11]. Taken together, these studies indicate that IRAK$M$ may attenuate TLR signaling and prevent excessive inflammation. However, the detailed molecular mechanism for IRAK-M-mediated suppression of the NFкB signaling network is not understood.

In this study, we examined the contribution of IRAK$M$ to the regulation of $\mathrm{NF \kappa B}$ signaling. Using wild-type and IRAK-M $^{-/}$bone-marrow-derived macrophages (BMDM), we have shown that IRAK-M disruption selectively enhanced the alternative pathway, in place of the classical NFKB pathway, in a ligand-specific manner. In addition, we performed computational simulation of the NFкB signaling network, which faithfully recapitulated our experimental observation.

\section{Materials and Methods}

\section{Mice}

C57BL/6 wild-type mice were purchased from the Charles River Laboratory. IRAK- $1^{-1-}$ mice were kindly provided by Dr. James Thomas from the University of Texas Southwestern Medical School. IRAK-M $\mathrm{M}^{-/-}$mice were kindly provided by Dr. Richard A. Flavell from the Yale University School of Medicine. These mice were bred and maintained in the animal facility at Virginia Tech according to the approved Animal Care and Use Committee protocol. All mice were 7-10 weeks of age when all experiments were initiated.

\section{Reagents}

The synthetic TLR2 agonist tripalmitoylated lipopeptide (tripalmitoylated-cysteine-serine-lysine-lysine-lysine-lysine) $\mathrm{Pam}_{3} \mathrm{CSK}_{4}$ was purchased from EMC Microcollections (Tübingen, Germany). Escherichia coli 0114 lipopolysaccharide (LPS) and anti-IRAK-M antibody were obtained from Sigma (St. Louis,
Mo., USA). The anti-IRAK-1 antibody was from Upstate Biotechnology (Lake Placid, N.Y., USA). The polyclonal antibody against $\mathrm{IkB} \alpha, \mathrm{p} 65, \mathrm{p}-\mathrm{p} 65, \mathrm{IKK} \alpha, \mathrm{IKK} \beta, \mathrm{p}-\mathrm{IKK} \alpha / \beta($ Ser 176/180) and $\mathrm{p}-$ IKK $\alpha / \beta$ (Ser 180/181) were from Cell Signal Biotechnology (Danvers, Mass., USA). The antibodies against TRAF6, RelB, p100/p52 and NIK were from Santa Cruz Biotechnology (Santa Cruz, Calif., USA). The NEMO monoclonal antibody was from BD Biosciences (San Jose, Calif., USA).

\section{Isolation and Culture of Murine BMDM}

Bone marrow from tibia and femur was obtained by flushing with DMEM. Bone marrow cells were cultured in a $125 \times 50 \mathrm{~mm}$ Lab-Tek non-tissue-culture-treated dish with $50 \mathrm{ml}$ of DMEM, containing 30\% L929 cell supernatant, $1 \mathrm{mM}$ sodium pyruvate, 50 $\mu \mathrm{M} 2$-mercaptoethanol and $2 \mathrm{mM}$ glutamine (Sigma). On the $3 \mathrm{rd}$ day of culture, cells were fed with additional $20 \mathrm{ml}$ fresh medium and cultured for an additional 3 days. Cells were harvested and washed with PBS, and resuspended in DMEM supplemented with $2 \mathrm{~mm}$ glutamine, 100 units $/ \mathrm{ml}$ penicillin, $100 \mathrm{mg} / \mathrm{ml}$ streptomycin (ICN, Aurora, Ohio, USA), and 10\% fetal bovine serum (Sigma). Cells were maintained at $37^{\circ} \mathrm{C}$ with $5 \% \mathrm{CO}_{2}$, and allowed to rest overnight before further treatment.

\section{Transfection of Small Interfering RNAs (siRNAs)}

siRNA against RelB and scrambled control siRNA were obtained from Santa Cruz Biotechnology and used to transfect IRAK-M-deficient BMDM using the lipofectamine reagent, as described by the manufacturer (Invitrogen, Carlsbad, Calif., USA). Transfected cells were incubated in DMEM with $10 \%$ fetal bovine serum, supplemented with 30\% L929 cell supernatant, $1 \mathrm{mM}$ sodium pyruvate, $50 \mu \mathrm{M} 2$-mercaptoethanol and $2 \mathrm{mM}$ glutamine for $72 \mathrm{~h}$, and subsequently used for further studies as described in the text.

\section{Isolation of Cytoplasmic and Nuclear Extracts and}

Western Blot

Cell lyses and isolation of total, cytoplasmic, and nuclear extracts were performed as described previously [12]. Briefly, various cells $\left(5 \times 10^{6} / \mathrm{ml}\right)$ were washed in $10 \mathrm{mM}$ HEPES, pH 7.9, and subsequently lysed on ice in the lysis buffer (10 mM HEPES, $\mathrm{pH}$ 7.9, $1.5 \mathrm{mM} \mathrm{MgCl}_{2}, 10 \mathrm{mM} \mathrm{KCl}, 0.5 \mathrm{~mm}$ EDTA, $0.5 \mathrm{mM}$ dithiothreitol, $0.5 \mathrm{~mm}$ phenylmethylsulfonyl fluoride, $1 \mu \mathrm{g} / \mathrm{ml} \mathrm{leu-}$ peptin, and $1 \mu \mathrm{g} / \mathrm{ml}$ pepstatin). After centrifugation for $10 \mathrm{~min}$ at 3,500 rpm, the supernatant cytoplasmic fractions were transferred and saved as cytoplasmic extracts. Pellets containing intact nuclei were lysed and solubilized with high salt buffer $(20 \mathrm{mM}$ HEPES, pH 7.9, $1.5 \mathrm{mM} \mathrm{MgCl}_{2}, 0.4 \mathrm{M} \mathrm{NaCl}, 0.2 \mathrm{~mm}$ EDTA, $0.5 \mathrm{~mm}$ dithiothreitol, and $1 \mathrm{mM}$ phenylmethylsulfonyl fluoride) for 30 min and yielded the nuclear extracts. Western blot analyses were performed as described [13].

\section{Cytokine Assay from Macrophages}

$2 \times 10^{6} \mathrm{BMDM}$ were seeded in 6-well plates in DMEM overnight and cultured with $\mathrm{Pam}_{3} \mathrm{CSK}_{4}$ or medium alone as indicated for $12 \mathrm{~h}$. An equal volume of RIPA buffer was added to the culture medium, and used to measure IL- 6 and GM-CSF levels using the Bio-Plex Cytokine assay as specified by the manufacturer (BioRad, Hercules, Calif., USA). 


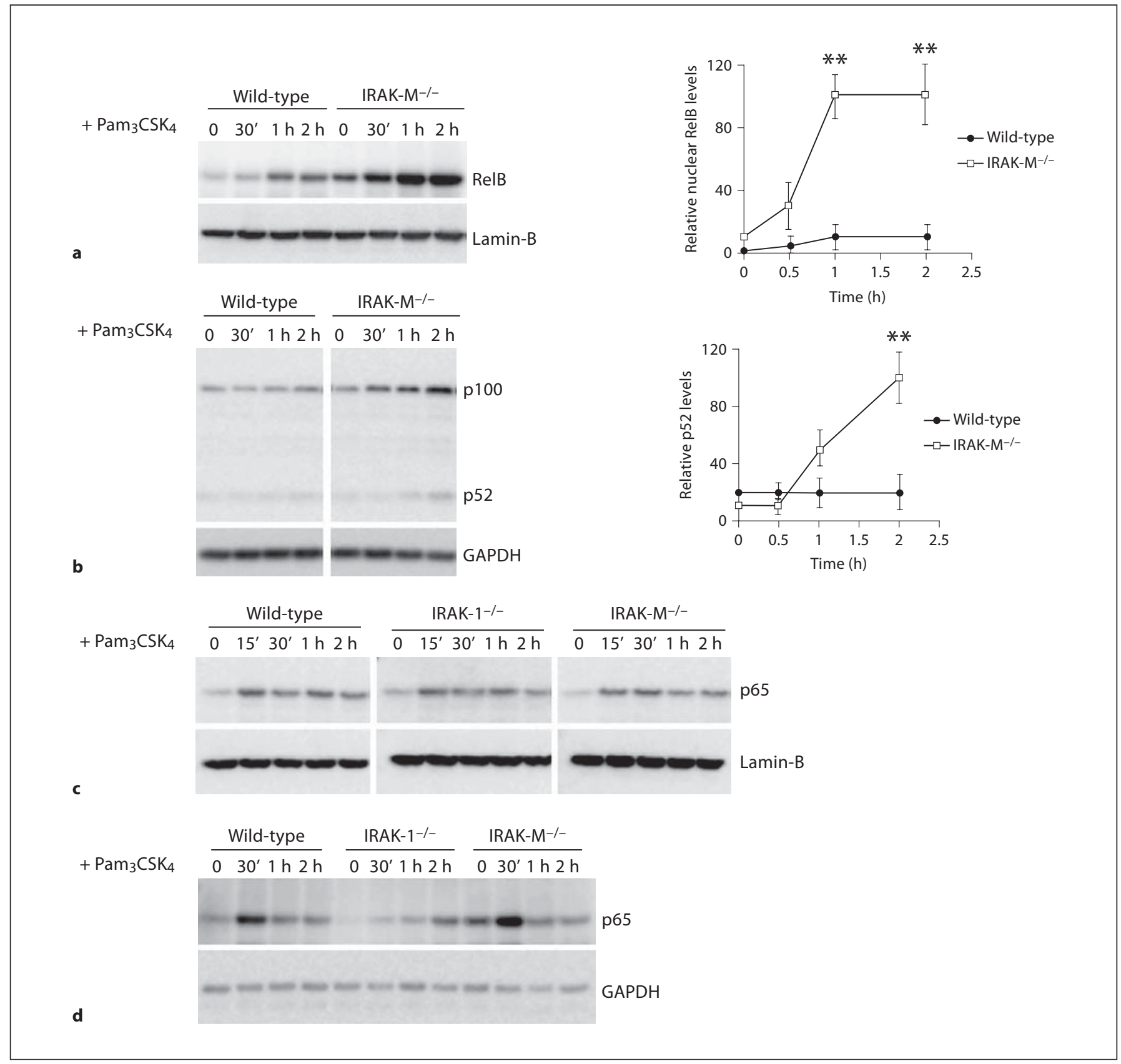

Fig. 1. IRAK-M selectively modulates the activation of RelB, not RelA-p65. a RelB nuclear translocation is increased in IRAK$\mathrm{M}^{-/-}$macrophages. BMDM from wild-type and IRAK-M ${ }^{-/-}$mice were stimulated with $100 \mathrm{ng} / \mathrm{ml}$ of $\mathrm{Pam}_{3} \mathrm{CSK}_{4}$ for the indicated time periods. Cell nuclear extracts were prepared as described in the Materials and Methods and blotted with anti-RelB or lamin-B antibodies. Lamin-B was a nuclear specific protein, and its levels served as a loading control. The relative levels of nuclear RelB adjusted with the loading controls were plotted in the right panel. ${ }^{* *} \mathrm{p}<0.05$. b IRAK-M deficiency results in constitutive processing of p100 in macrophages. BMDM from wild-type and IRAK$\mathrm{M}^{-/-}$mice were stimulated with $100 \mathrm{ng} / \mathrm{ml}$ of $\mathrm{Pam}_{3} \mathrm{CSK}_{4}$ for the indicated periods. Cell lysates were prepared and blotted with anti-p100/p52 antibody as well as the control GAPDH antibody. The relative p52 intensities adjusted with loading controls were plotted in the right panel. ${ }^{* *} \mathrm{p}<0.05$. c Nuclear p65 levels are similar in IRAK-M ${ }^{-/-}$, wild-type and IRAK1 ${ }^{-/-}$BMDM. BMDM were stimulated with $100 \mathrm{ng} / \mathrm{ml}$ of $\mathrm{Pam}_{3} \mathrm{CSK}_{4}$ for the indicated times. Cell nuclear extracts were prepared and blotted with antip65 antibody. Lamin-B was used as a loading control. d A similar pattern of 65 phosphorylation at Ser536 among wild-type, IRAK$1^{-/-}$, and IRAK-M ${ }^{-/-}$macrophages. BMDM from wild-type, $\mathrm{IRAK}^{-/-}$, and IRAK-M ${ }^{-/-}$mice were stimulated with $100 \mathrm{ng} / \mathrm{ml}$ of $\mathrm{Pam}_{3} \mathrm{CSK}_{4}$ for the indicated time periods. Cell lysates were prepared and blotted with anti-p65phospho-Ser536 antibody. 
Table 1. Differential equations and parameters

The IKK $\alpha$ module

$$
\begin{aligned}
& \frac{d[\mathrm{NIK}]}{d t}=k_{\mathrm{sNIK}}^{\prime}+\frac{k^{\prime \prime}{ }_{\mathrm{sNI}} \text { Signal }}{J^{\prime}{ }_{\mathrm{sNIK}}+J^{\prime \prime}{ }_{\mathrm{sNIK}}[\mathrm{IRAKm}]}-k_{\mathrm{dNIK}}[\mathrm{NIK}] \\
& \frac{d[\mathrm{IKKa \textrm {P }}]}{d t}=\frac{k_{\mathrm{pIKKa}}[\mathrm{IKKa}]}{J_{\mathrm{pIKKa}}+[\mathrm{IKKa}]}-\frac{k_{\mathrm{dpIKKa}}[\mathrm{IKKaP}]}{J_{\mathrm{dpIKKa}}+[\mathrm{IKKaP}]} \\
& \frac{d[\mathrm{IMa}]}{d t}=\frac{k_{\mathrm{aIM}}[\mathrm{IKKaP}][\mathrm{IMi}]}{J_{\mathrm{aIM}}+[\mathrm{IMi}]}-\frac{k_{\mathrm{iIM}}[\mathrm{IMa}]}{J_{\mathrm{iIM}}+[\mathrm{IMa}]} \\
& \frac{d[\mathrm{PP} 2 \mathrm{~A}]}{d t}=\frac{k_{\mathrm{aPP}}[\mathrm{IMa}][\mathrm{PP} 2 \mathrm{Ai}]}{J_{\mathrm{aPP}}+[\mathrm{PP} 2 \mathrm{Ai}]}-\frac{k_{\mathrm{iPP}}[\mathrm{PP} 2 \mathrm{~A}]}{J_{\mathrm{iPP}}+[\mathrm{PP} 2 \mathrm{~A}]}
\end{aligned}
$$

$[\mathrm{IKK} \alpha]=\left[\mathrm{IKK} \alpha_{\text {total }}\right]-[\mathrm{IKK} \alpha \mathrm{P}]$

$[\mathrm{IMi}]=\left[\mathrm{IM}_{\text {total }}\right]-[\mathrm{IMa}]$

$k_{\text {pIKKa }}=k_{\text {pIKKa }}^{\prime}+k_{\text {pIKKa }}^{\prime \prime}[\mathrm{NIK}]$

$k_{\text {dpIKKa }}=k_{\text {dpIKKa }}^{\prime}+k_{\text {dpIKKa }}^{\prime \prime}[\mathrm{PP} 2 \mathrm{~A}]$

$[\mathrm{PP} 2 \mathrm{Ai}]=\left[\mathrm{PP} 2 \mathrm{~A}_{\text {total }}\right]-[\mathrm{PP} 2 \mathrm{~A}]$

$k_{\mathrm{sNIK}}=2, k^{\prime \prime}{ }_{\mathrm{SNIK}}=16$

$k_{\mathrm{dNIK}}=20, J^{\prime}{ }_{\mathrm{SNIK}}=1, J^{\prime \prime}{ }_{\mathrm{SNIK}}=100$

$\left[\mathrm{IKK} \alpha_{\text {total }}\right]=1,\left[\mathrm{PP} 2 \mathrm{~A}_{\text {total }}\right]=1,\left[\mathrm{IM}_{\text {total }}\right]=1$

$k_{\text {pIKKa }}^{\prime}=0.001, k_{\text {pIKKa }}^{\prime \prime}=0.1, J_{\text {pIKKa }}=0.1$

$k_{\text {dpIKKa }}^{\prime}=0.01, k_{\text {dpIKKa }}^{\prime \prime}=0.1, J_{\text {dpIKKa }}=0.1$

$k_{\mathrm{aIM}}=0.1, J_{\mathrm{aIM}}=0.1, k_{\mathrm{iIM}}=0.03, J_{\mathrm{iIM}}=0.1$

$k_{\mathrm{aPP}}=0.1, J_{\mathrm{aPP}}=0.1, k_{\mathrm{iPP}}=0.05, J_{\mathrm{iPP}}=0.1$

The IKK $\beta$ module

$\frac{d[\mathrm{PPX}]}{d t}=\frac{k_{a P P X} \text { Signal }\left[\mathrm{PPX}_{\mathrm{in}}\right]}{J_{a P P X}+\left[\mathrm{PPX}_{\mathrm{in}}\right]}-\frac{k_{\text {inPPX }}[\mathrm{PPX}]}{J_{\text {inPPX }}+[\mathrm{PPX}]}$

$\frac{d[\mathrm{IKK} \beta]}{d t}=\frac{k_{a c \mathrm{KKK} \beta} \operatorname{Signal}[\mathrm{IRAKm}]\left[\mathrm{IKK} \beta_{\mathrm{in}}\right]}{J_{a c \mathrm{KK} \beta}+\left[\mathrm{IKK} \beta_{\mathrm{in}}\right]}-\frac{k_{i n \mathrm{IKK} \beta}[\mathrm{PPX}][\mathrm{IKK} \beta]}{J_{i n \mathrm{IKK} \beta}+[\mathrm{IKK} \beta]}$

$\left[\mathrm{IKK} \beta_{\text {in }}\right]=\left[\mathrm{IKK} \beta_{\text {total }}\right]-[\mathrm{IKK} \beta]$

$\left[\mathrm{PPX}_{\mathrm{in}}\right]=\left[\mathrm{PPX}_{\text {total }}\right]-[\mathrm{PPX}]$

$\left[\mathrm{IKK} \beta_{\text {total }}\right]=2,[\mathrm{PPX}$ total $]=2,[\mathrm{IRAKm}]=1$

$k_{a P P X}=0.016, k_{\text {inPPX }}=0.0008, J_{a P P X}=0.1, J_{\text {inPPX }}=0.1$

$k_{a c \mathrm{IKK} \beta}=0.4, k_{\mathrm{inIKK} \beta}=1.6, J_{a c \mathrm{IKK} \beta}=0.1, J_{\text {inIKK } \beta}=0.1$
The NF-кB module

$$
\begin{aligned}
& \frac{d[\mathrm{RelB}]}{d t}=\frac{k_{s \mathrm{RelB}}}{J^{\prime}{ }_{\text {sRelB }}+J^{\prime \prime}{ }_{s \mathrm{RelB}}[\mathrm{IRAKm}]}-k_{d \mathrm{RelB}}[\mathrm{RelB}] \\
& \frac{d[\mathrm{am}]}{d t}=k_{\text {sam }}^{\prime}+\frac{k^{\prime \prime}{ }_{\text {sam }}[\mathrm{nn}]^{2}}{[\mathrm{nn}]^{2}+J^{\prime \prime}{ }_{\text {sam }}^{2}}-k_{d a m}[\mathrm{am}] \\
& \frac{d[\mathrm{ac}]}{d t}=k_{s a c}[\mathrm{am}]-k_{a s d c a}[\mathrm{nc}][\mathrm{ac}]+k_{d s d c a}[\mathrm{dca}]-k_{a i}[\mathrm{ac}]+k_{a o}[\mathrm{an}]- \\
& \left(k_{d a c}^{\prime}+k_{d a c}^{\prime \prime}[\mathrm{IKK}]\right)[\mathrm{ac}] \\
& \frac{d[\mathrm{an}]}{d t}=k_{a i}[\mathrm{ac}]-k_{a o}[\mathrm{an}]-k_{a s d n a}[\mathrm{nn}][\mathrm{an}]+k_{d s d n a}[\mathrm{dna}] \\
& \frac{d[\mathrm{nn}]}{d t}=k_{n i}[\mathrm{nc}]-k_{n o}[\mathrm{nn}]-k_{a s d n a}[\mathrm{nn}][\mathrm{an}]+k_{d s d n a}[\mathrm{dna}] \\
& \frac{d[\mathrm{dna}]}{d t}=k_{a s d n a}[\mathrm{nn}][\mathrm{an}]-k_{d s d n a}[\mathrm{dna}]+k_{d i a}[\mathrm{dca}]-k_{d o a}[\mathrm{dna}] \\
& \frac{d[\mathrm{dca}]}{d t}=k_{\text {asdca }}[\mathrm{nc}][\mathrm{ac}]-k_{d s d c a}[\mathrm{dca}]-k_{d i a}[\mathrm{dca}]+k_{d o a}[\mathrm{dna}]- \\
& \left(k_{d d c a}^{\prime}+k_{d d c a}^{\prime \prime}[\mathrm{IKK}]\right)[\mathrm{dca}] \\
& {[\mathrm{IKK}]=[\mathrm{IKK} \alpha]+[\mathrm{IKK} \beta]} \\
& {\left[\mathrm{IKB} \alpha_{\text {total }}\right]=[\mathrm{ac}]+[\mathrm{an}]+[\mathrm{dca}]+[\mathrm{dna}]} \\
& {\left[\mathrm{NF} \kappa \mathrm{B}_{\text {total }}\right]=[\operatorname{RelA}]+[\operatorname{RelB}]} \\
& {[\mathrm{nc}]=\left[\mathrm{NF} \kappa \mathrm{B}_{\text {total }}\right]-[\mathrm{nn}]-[\mathrm{dna}]-[\mathrm{dca}]} \\
& {[\operatorname{RelA}]=0.5, k_{s \operatorname{RelB}}=12, J^{\prime}{ }_{s \operatorname{RelB}}=1, J^{\prime \prime}{ }_{s \operatorname{Rel}}=100,{ }_{d \operatorname{RelB}}=20} \\
& k_{\text {sam }}^{\prime}=0.1696, k_{\text {sam }}^{\prime \prime}=0.4772, J_{\text {sam }}^{\prime \prime}=0.1, k_{\text {dam }}=0.12 \\
& k_{\text {sac }}=0.2896, k_{\text {asdca }}=60, k_{d s d c a}=0.0012, k_{a i}=0.036, k_{a o}=0.024 \text {, } \\
& k_{d a c}^{\prime}=0.024, k_{d a c}^{\prime \prime}=0.2 \\
& k_{\text {dia }}=0.02, k_{d o a}=1.656, k_{d d c a}^{\prime}=0.06, k_{d d c a}^{\prime \prime}=0.72 \\
& k_{n i}=10.8, k_{n o}=0.0096, k_{a s d n a}=60, k_{d s d n a}=0.00012
\end{aligned}
$$

\section{Computational Modeling of NFKB Pathways}

The model is composed of three modules, one for IKK $\alpha$, one for IKK $\beta$ and the third for NFкB and IкB $\alpha$. This modular approach allows for easy analysis of individual parts of the complex system. It also facilitates the inherence of previous models. Since the negative feedback between NFкB and IкB $\alpha$ has already been intensively studied, we can incorporate it as a module. All the equations and parameters are listed in table 1 . The model contains both dimensional and dimensionless parameters. Since the time series data and degradation rates are easiest to achieve experimentally, the time unit is set in minutes and the degradation rates have the units of $\mathrm{min}^{-1}$. All other parameters and variables are dimensionless; they are combinations of several biological components. Values for the rate constants were chosen by a trial-and-error method to provide simulations with other experimental observations. IRAK-M is set to one and zero in wild-type and IRAK-M-deficient models, respectively. The systems are allowed to reach steady states in the absence of a signal. Their simulations begin from these steady states. The signal is set to 0.5 to mimic the effect of $\mathrm{Pam}_{3} \mathrm{CSK}_{4}$. Numerical integration of the ordinary differential equations is carried out with XPPAUT, which is freely downloadable from http://www. math.pitt.edu/ bard/xpp/xpp.html. Differential equations used to generate the model are listed in table 1. 
Statistical Analyses

Statistical significance was determined using the unpaired 2tailed Student $t$ test or 1-way ANOVA corrected for multiple comparisons where appropriate. $\mathrm{p}<0.05$ was considered statistically significant. All calculations were performed using the Prism 4.03 software program for Windows (GraphPad Software).

\section{Results}

IRAK-M Selectively Modulates RelB, but Not p65, Activity in BMDM

In order to explore how IRAK-M inhibits NFкB activation and negatively regulates TLR signaling, we stimulated BMDM from wild-type and IRAK-M ${ }^{-l-}$ mice with $100 \mathrm{ng} / \mathrm{ml} \mathrm{Pam}_{3} \mathrm{CSK}_{4}$ for various time periods. Nuclear lysates from treated cells were harvested, and equal amounts of nuclear lysates were separated on SDS-PAGE. As shown in figure 1a, nuclear RelB levels were low and unaltered following $\mathrm{Pam}_{3} \mathrm{CSK}_{4}$ challenge in wild-type cells, indicating the lack of RelB activation. In contrast, RelB levels were significantly increased in IRAK-M ${ }^{-/}$ cells. Since the nuclear translocation of RelB depends on the cleavage of $\mathrm{p} 100$ to $\mathrm{p} 52$, we measured the processing of p100 to p52 in whole-cell lysates. As shown in figure lb, $\mathrm{Pam}_{3} \mathrm{CSK}_{4}$ challenge induced a gradual cleavage of p100 and an increased formation of p52 in IRAK-M ${ }^{-/-}$ cells, but not in wild-type BMDM.

To clarify whether IRAK-M affects the classical NFкB pathway leading to p65 activation, we further examined nuclear p65 protein levels. As shown in figure 1c, $\mathrm{Pam}_{3} \mathrm{CSK}_{4}$ stimulation induced the nuclear translocation of p65 to a similar extent among wild-type, IRAK1 ${ }^{-/-}$or IRAK-M $^{-/-}$BMDM. Since the transcriptional activity of p65 can be further influenced by phosphorylation, we measured the levels of p65 Ser536 phosphorylation in whole cell lysates. We observed that $\mathrm{Pam}_{3} \mathrm{CSK}_{4}$ stimulation induced a similar pattern of $\mathrm{p} 65$ Ser536 phosphorylation in wild-type and IRAK-M ${ }^{-/-}$BMDM. Intriguingly, we found that the p65 phosphorylation was significantly attenuated in IRAK1 ${ }^{-/-}$BMDM, indicating that IRAK-1 is involved in $\mathrm{Pam}_{3} \mathrm{CSK}_{4}$-induced phosphorylation, but not nuclear localization of $\mathrm{p} 65$.

\section{IRAK-M Disruption Contributes to the \\ Stabilization of NIK}

Since the alternative NFKB signaling pathway relies on the NIK [14], we subsequently examined the status of NIK in wild-type and IRAK-M ${ }^{-/-}$macrophages. Whole-cell lysates from wild-type and IRAK-M ${ }^{-/-}$BMDM stimulated with $\mathrm{Pam}_{3} \mathrm{CSK}_{4}$ were prepared and blotted with NIK

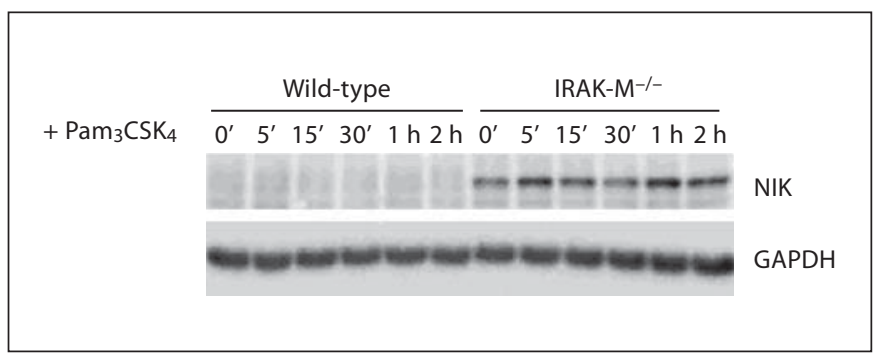

Fig. 2. IRAK-M disruption contributes to the stabilization of NIK. Bone marrow-derived macrophages from wild-type and IRAK$\mathrm{M}^{-/-}$mice were stimulated with $100 \mathrm{ng} / \mathrm{ml}$ of $\mathrm{Pam}_{3} \mathrm{CSK}_{4}$ for the indicated time periods. Cell lysates were prepared and blotted with anti-NIK antibody.

antibody. As shown in figure 2, NIK levels were not detectable in wild-type BMDM, consistent with previous findings [15]. In contrast, NIK levels were readily and constitutively detected in IRAK-M ${ }^{-/-}$BMDM (fig. 2).

\section{IRAK-M Disruption Leads to Elevated IKK $\alpha$}

\section{Phosphorylation at Ser176, but Not at Ser180}

The activation of NIK was shown to selectively induce IKK $\alpha$ phosphorylation and subsequent processing of p100 [16]. We therefore examined the IKK $\alpha$ phosphorylation status using the phosphor-specific antibodies against phosphorylated IKK $\alpha / \beta$. First, we used the antibody that can recognize phosphorylated IKK $\alpha$ Ser180/ IKK $\beta$ Ser181. As shown in figure 3, we found that $\mathrm{Pam}_{3} \mathrm{CSK}_{4}$ stimulation induced similar levels of IKK $\alpha /$ IKK $\beta$ phosphorylation at Ser180/Ser181 sites compared with wild-type and IRAK-M ${ }^{-/-}$BMDM. Subsequently, we employed the antibody that recognizes phosphorylated IKK $\alpha$ Ser176/Ser180 and IKK $\beta$ Ser177/Ser181. Following $\mathrm{Pam}_{3} \mathrm{CSK}_{4}$ stimulation, we observed significantly increased bands representing phosphorylated IKK $\alpha$ Ser176/Ser180 as well as IKK $\beta$ Ser177/Ser181 in IRAK$\mathrm{M}^{-/-}$BMDM (fig. 3). Taken together, these results indicate that IRAK-M specifically modulates phosphorylation of IKK $\alpha$ Ser176/IKK $\beta$ Ser177 instead of IKK $\alpha$ Ser 180/IKK $\beta$ Ser181.

\section{IRAK-M Deficiency Leads to Preferential Interaction}

of NEMO with IKK $\alpha$ Instead of IKK $\beta$

It has been shown that NIK activation favors the formation of the IKK $\alpha / \mathrm{IKK} \alpha$ homodimer instead of the IKK $\alpha /$ IKK $\beta$ heterodimer. To explore whether IRAK-M may affect the stoichiometry of the NEMO/IKK $\alpha / \mathrm{IKK} \beta$ complex, we performed NEMO co-immunoprecipita- 


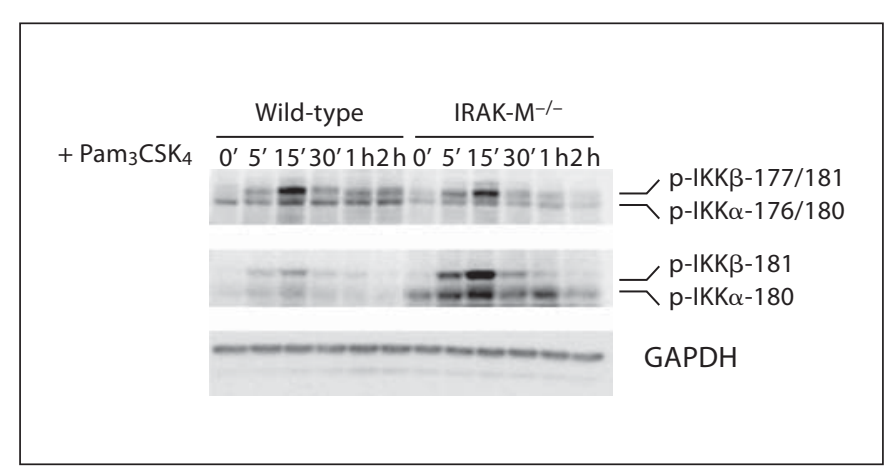

Fig. 3. IRAK-M disruption leads to elevated IKK $\alpha$ phosphorylation at Ser176. BMDM from wild-type and IRAK-M ${ }^{-/-}$mice were stimulated with $100 \mathrm{ng} / \mathrm{ml}$ of $\mathrm{Pam}_{3} \mathrm{CSK}_{4}$ for the indicated time periods. Cell lysates were prepared and blotted with anti-phospho-IKK $\alpha / \beta$ (Ser176/Ser180), and anti-phospho-IKK $\alpha$ (Ser180)/ IKK $\beta$ (Ser181) antibodies.

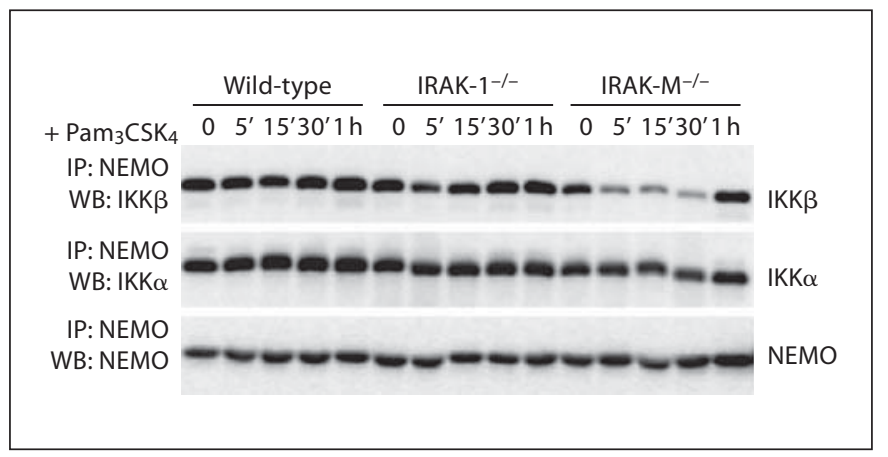

Fig. 4. IRAK-M disruption skews the IKK complex in favor of the IKK $\alpha / \mathrm{IKK} \alpha$ homodimer. BMDM from wild-type, IRAK $1^{-/-}$and IRAK-M ${ }^{-/-}$mice were stimulated with $100 \mathrm{ng} / \mathrm{ml}$ of $\mathrm{Pam}_{3} \mathrm{CSK}_{4}$ for the indicated time periods. Cell lysates were immunoprecipitated with an anti-NEMO antibody. Immunoprecipitates were separated on SDS-PAGE, and probed with antibodies against either IKK $\alpha$, IKK $\beta$, or NEMO.
Fig. 5. Elevated alternative $\mathrm{NF \kappa B}$ pathway in IRAK-M-deficient cells contributes to quickened synthesis of I $\mathrm{B} \alpha$, as well as elevated expression of GM-CSF and IL-6. BMDM from wild-type, IRAK1 $1^{-/-}$and IRAK-M ${ }^{-/-}$mice were stimulated with 100 $\mathrm{ng} / \mathrm{ml}$ of $\mathrm{Pam}_{3} \mathrm{CSK}_{4}$ for the indicated time periods. Cell lysates were prepared and blotted with antibodies against I $\kappa \alpha$ or $\beta$ actin. The relative $\mathrm{I} \kappa \mathrm{B} \alpha$ levels in wildtype, IRAK-1 $1^{-/}$and IRAK-M ${ }^{-/-}$BMDM from three independent experiments were plotted at the bottom. b BMDM from wildtype and IRAK-M ${ }^{-/-}$mice were plated in 6 -well plates at a density of $3 \times 10^{6}$ cells/ well. Cells were stimulated with $100 \mathrm{ng} / \mathrm{ml}$ of $\mathrm{Pam}_{3} \mathrm{CSK}_{4}$. After $12 \mathrm{~h}$, the expression levels of GM-CSF and IL-6 were assayed. The data represent three independent experiments. ${ }^{* *} \mathrm{p}<0.05$.

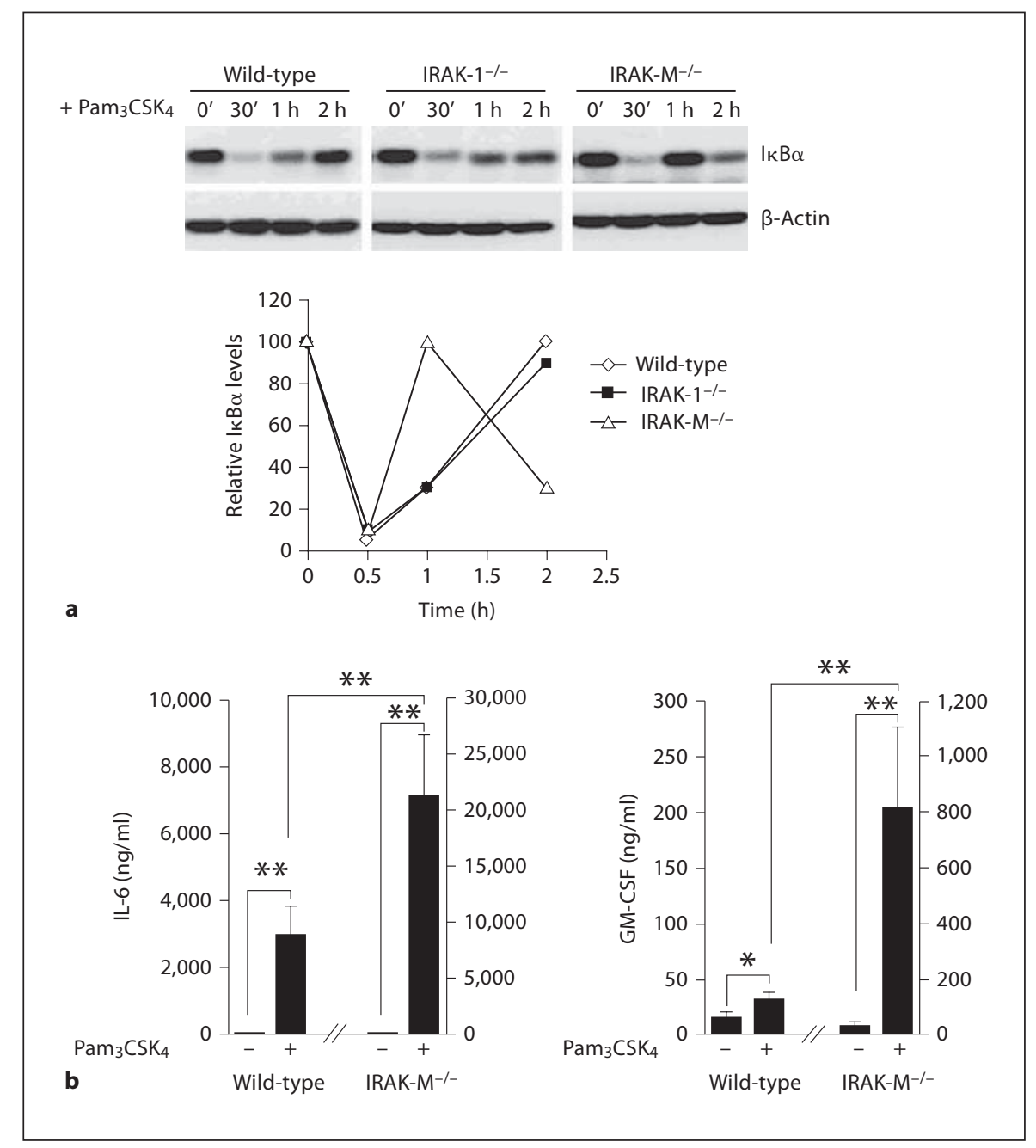


Fig. 6. siRNA knockdown of RelB in IRAK-M-deficient cells attenuates IL- 6 and GM-CSF expression in IRAK$\mathrm{M}$ cells. BMDM from IRAK-M ${ }^{-/-}$mice were transfected with control or RelB-specific siRNA as described in the Materials and Methods. The transfected cells were subsequently stimulated with $100 \mathrm{ng} / \mathrm{ml}$ of $\mathrm{Pam}_{3} \mathrm{CSK}_{4}$ for $12 \mathrm{~h}$. The expression levels of GM-CSF and IL- 6 were assayed and plotted. ${ }^{* *} \mathrm{p}<0.05$.

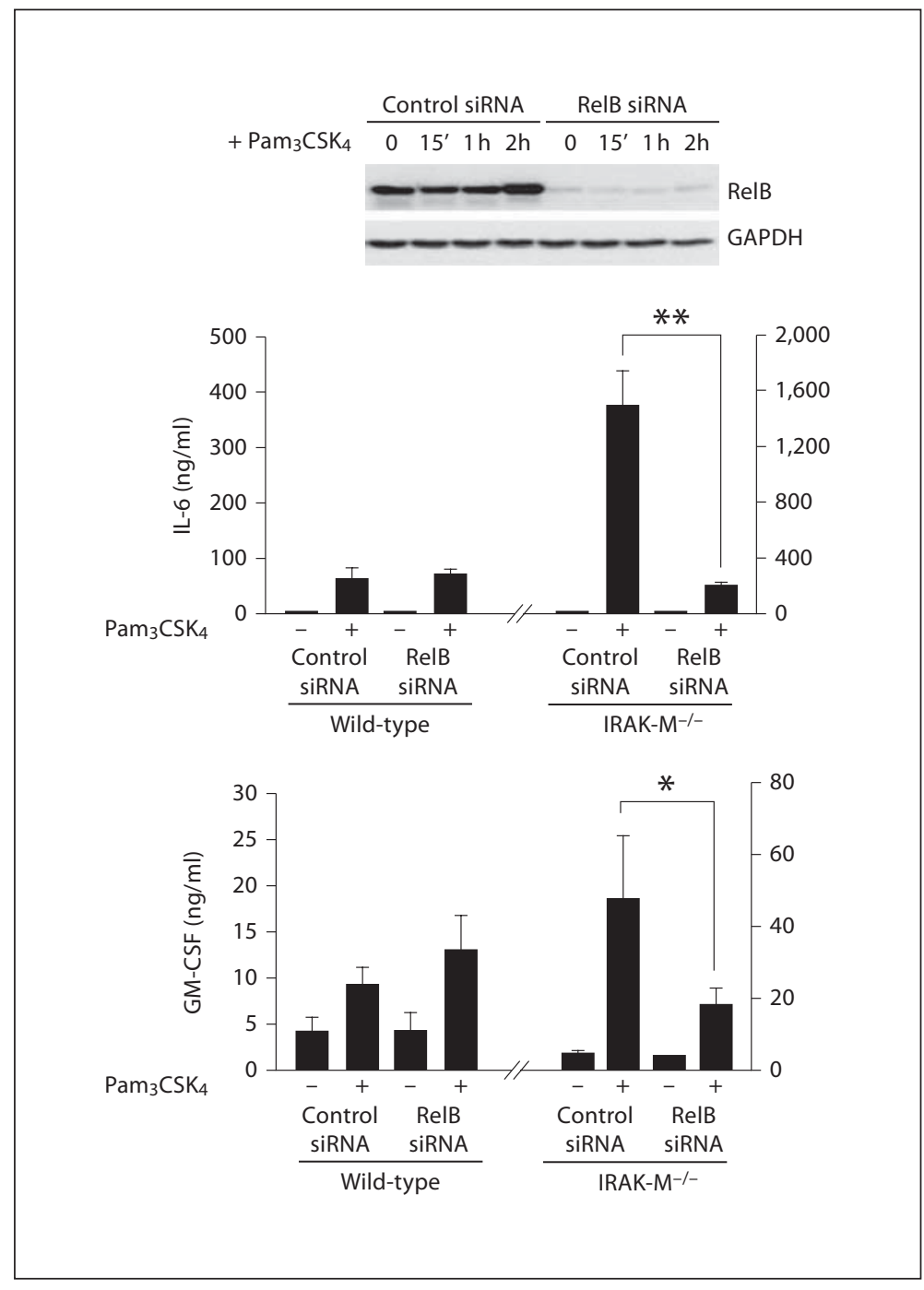

tion assays using whole-cell lysates from wild-type, IRAK- ${ }^{-/-}$and IRAK-M ${ }^{-/}$BMDM. The immunoprecipitated samples were blotted with IKK $\alpha$ or IKK $\beta$ antibody. Comparing wild-type and IRAK- $1^{-/-}$samples, we observed that the levels of IKK $\alpha$ and IKK $\beta$ proteins within the co-immunoprecipitated NEMO complex were similar and remained constant following stimulation. In sharp contrast, we found that the levels of IKK $\beta$ within the co-immunoprecipitated NEMO complex dropped sharply in IRAK-M ${ }^{-/}$BMDM following 15 min of stimulation, and returned back to normal levels $1 \mathrm{~h}$ later. The levels of IKK $\alpha$ in the NEMO complex remained constant throughout the stimulation period, indicating that IRAK-M deficiency favors the formation of the $\mathrm{NEMO} / \mathrm{IKK} \alpha / \mathrm{IKK} \alpha$ homodimer following challenge with $\mathrm{Pam}_{3} \mathrm{CSK}_{4}$ (fig. 4).
Elevated Alternative NF $\kappa B$ Pathway in

IRAK-M-Deficient Cells Contributes to Quickened Synthesis of $I \kappa B \alpha$, as well as Elevated Expression of GM-CSF and IL-6

In wild-type cells, I $\mathrm{B} \alpha$ was quickly degraded following $\mathrm{Pam}_{3} \mathrm{CSK}_{4}$ stimulation, leading to the nuclear translocation and activation of p65. In turn, p65 contributed to the transcription and synthesis of new $\operatorname{I\kappa } B \alpha$, which gradually increased back to the peak resting level $2 \mathrm{~h}$ after the start of stimulation (fig. 5). We observed a similar pattern of IкB $\alpha$ degradation and gradual resynthesis in IRAK- $1^{-1-}$-deficient cells. Intriguingly, we found that the I $\mathrm{B} \alpha$ levels were resynthesized significantly quicker in IRAK-M $^{-/}$cells, presumably due to synergistic activation of both the classical and alternative pathways. As shown in figure 5, ІкВ $\alpha$ returned back to the peak resting 
Fig. 7. The effect of IRAK-M is ligand specific. a BMDM from wild-type, IRAK1 ${ }^{-/-}$ and IRAK-M ${ }^{-/-}$mice were stimulated with $100 \mathrm{ng} / \mathrm{ml}$ of LPS for the indicated time periods. Cell lysates were prepared and blotted with antibodies against either Iк $\mathrm{B} \alpha$ or $\beta$-actin. b BMDM from wild-type and IRAK-M $^{-/-}$mice were plated in 6-well plates at a density of $3 \times 10^{6}$ cells/well. Cells were stimulated with $100 \mathrm{ng} / \mathrm{ml}$ of LPS. After $12 \mathrm{~h}$, the expressed levels of GM-CSF and IL- 6 were assayed and plotted.

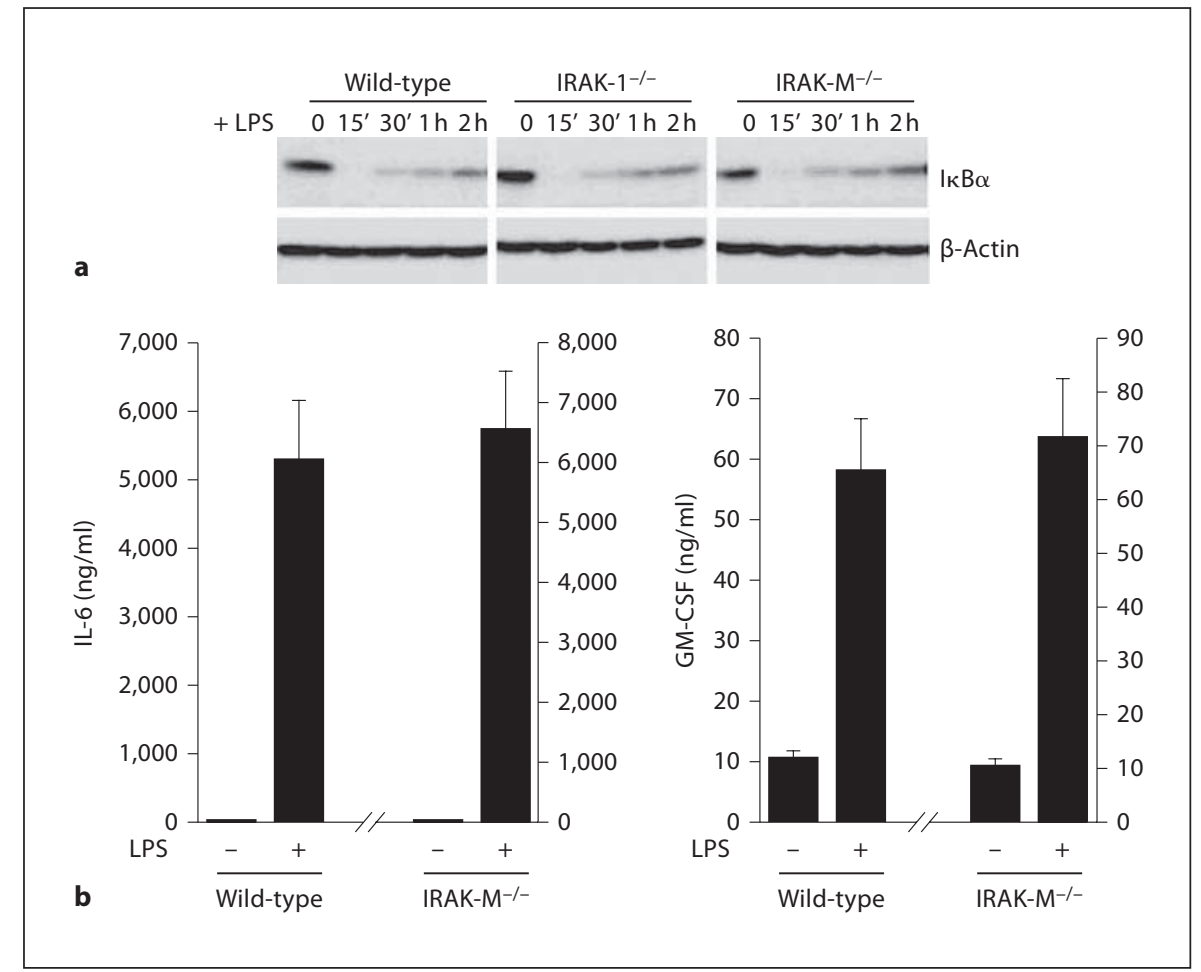

level 60 min after the start of stimulation in IRAK-M ${ }^{-/-}$ cells. Furthermore, ІкВ $\alpha$ underwent a second wave of degradation in IRAK-M ${ }^{-/}$cells. Correspondingly, we noticed that there was a second wave of IKK $\alpha$ phosphorylation at Ser176/Ser180 60 min after $\mathrm{Pam}_{3} \mathrm{CSK}_{4}$ stimulation in IRAK-M ${ }^{-/}$cells. This phenomenon may be responsible for the subsequent phosphorylation and degradation of newly synthesized ІкB $\alpha$ (fig. 3).

We further measured the levels of selected cytokines using the Bio-Plex Cytokine assay as described in the Materials and Methods. The levels of IL-6 and GM-CSF were very low in resting wild-type BMDM, and were induced following $\mathrm{Pam}_{3} \mathrm{CSK}_{4}$ stimulation. In contrast, $\mathrm{Pam}_{3} \mathrm{CSK}_{4}$ stimulation induced significantly higher amounts of IL-6 and GM-CSF in IRAK-M ${ }^{-/-}$macrophages (fig. 5b). In order to determine whether the enhanced RelB activation in IRAK-M ${ }^{-/}$BMDM was responsible for the elevated IL-6 and GM-CSF expression, we performed the siRNA knockdown experiment. IRAK$\mathrm{M}^{-/-}$BMDM were transfected with either control siRNA or RelB-specific siRNA. Transfected cells were subsequently stimulated with $\mathrm{Pam}_{3} \mathrm{CSK}_{4}$ for $16 \mathrm{~h}$. As shown in figure 6, IRAK-M ${ }^{-/-}$BMDM transfected with RelB-specific siRNA had significantly decreased expression of IL-6 and GM-CSF.

IRAK-M Suppressing the Alternative NFкB Pathway
The Effect of IRAK-M Is Ligand Specific

Because different TLRs may trigger distinct downstream signaling pathways, we examined the involvement of IRAK-M in LPS-TLR4-mediated signaling. BMDM isolated from wild-type, IRAK- $1^{-/}$and IRAK$\mathrm{M}^{-/-}$mice were stimulated with LPS for the indicated time periods. In contrast to the phenomenon obtained with $\mathrm{Pam}_{3} \mathrm{CSK}_{4}$ stimulation, we observed a similar pattern of I $\kappa \mathrm{B} \alpha$ degradation and resynthesis among wildtype, IRAK-1 $1^{-/}$and IRAK-M ${ }^{-/}$BMDM following LPS challenge (fig. 7). We further measured the expression levels of IL- 6 and GM-CSF by Bio-Plex cytokine assay. Correspondingly, we observed that LPS induced similar levels of IL-6 and GM-CSF among wild-type and IRAK$\mathrm{M}^{-/-}$BMDM (fig. 7).

\section{Discussion}

In this study, we have demonstrated that IRAK-M is primarily involved in regulating the alternative, instead of the canonical NFKB pathway. Several lines of evidence support this conclusion. First, the patterns of p65/RelA nuclear translocation and phosphorylation are identical following $\mathrm{Pam}_{3} \mathrm{CSK}_{4}$ challenge between wild-type and

J Innate Immun 2009;1:164-174 

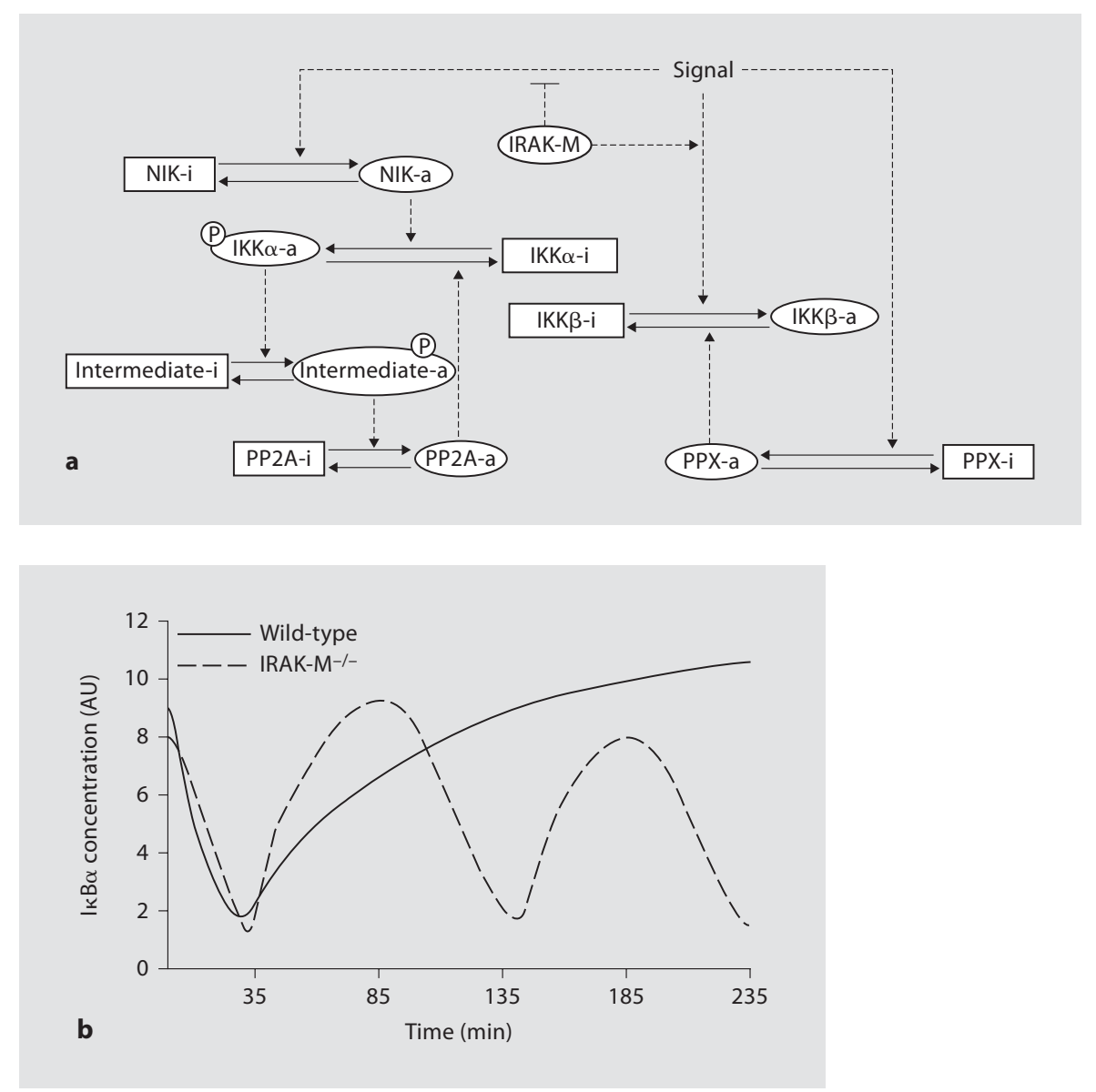

Fig. 8. Computation simulation of IRAK-M-mediated NFкB regulation. a The wiring diagram regarding the function of IRAK-M. Labeled boxes and ovals represent protein components of the model. Solid lines indicate chemical transformations between active (-a) and inactive (-i) forms of a protein. Dashed lines indicate regulatory and catalytic effects. Arrow heads and cross bars on the dashed lines indicate activation and inhibition, respectively. Specifically, NIK-a represents the stabilized and activated form of NIK; the dashed line with an arrow head shows that NIK stabilization and activation are enhanced by the 'signal'; the dashed line with a cross bar indicates that the signal-induced stabilization and activation of NIK are inhibited by IRAK-M. $\mathbf{b}$ The computational simulation of the I $\mathrm{B} \alpha$ degradation and re-occurrence. In

IRAK-M $^{-/-}$cells. Second, IRAK-M ${ }^{-/}$cells have elevated levels of NIK protein, as well as an increased nuclear distribution of RelB. Third, IRAK-M ${ }^{-/-}$cells favored the formation of the IKK $\alpha / \mathrm{IKK} \alpha$ homodimer instead of the IKK $\alpha /$ IKK $\beta$ heterodimer. Consequently, IRAK-M deficiency contributes to synergistic and overall activation of the $\mathrm{NF \kappa B}$ pathway, leading to elevated expression of $\mathrm{cy}$ tokines, such as IL-6 and GM-CSF. resting cells, I $\mathrm{B} \alpha$ level is high. In the wild-type cells with the functional IRAK-M, the stimulus signal results in the activation of the classical pathway and profound IKK $\beta$ activation. In contrast, IKK $\alpha$ is kept inactive due to the lack of active NIK (a). IKK $\beta$ phosphorylates IкB $\alpha$ and enhances its degradation. Therefore, the IK $B \alpha$ level decreases (solid line). Later on, IKK $\beta$ is inactivated by an unknown mechanism (potentially through a phosphatase as represented by PPX), and the I $\mathrm{B} \alpha$ level recovers. In the absence of IRAK-M, NIK protein is stabilized and activated which contributes to the elevated IKK $\alpha$ activity (a). IKK $\alpha$ activity is likely controlled by other negative feedback loops (e.g. protein phosphatase PP2A, a). Collectively, these give rise to the oscillating levels of $\mathrm{I} \kappa \mathrm{B} \alpha$ (dashed line).

Extensive studies regarding the regulation of the NFKB pathway have revealed a complex network involving multiple positive and negative regulatory pathways and loops. These intertwined signaling pathways help host cells to elicit precise, complex, and subtle responses following diverse challenges [17]. However, further clarification regarding the fine regulation of the NFкB signaling network is still required. Our current study reveals a novel 
mechanism for IRAK-M-mediated preferential suppression of the alternative $\mathrm{NF \kappa B}$ signaling pathway. In the absence of IRAK-M, the level of NIK is elevated, which contributes to skewed IKK complex formation. The skewed IKK complex favors the formation of the IKK $\alpha$ / IKK $\alpha$ homodimer instead of the IKK $\alpha /$ IKK $\beta$ heterodimer. The elevated NIK-IKK $\alpha / \mathrm{IKK} \alpha$ pathway subsequently contributes to the overall perturbed NFKB network, as reflected by quickened resynthesis of Iк $B \alpha$ and a second wave of I $\mathrm{B} \alpha$ degradation. By employing computational simulation based upon existing $\mathrm{NF \kappa B}$ signaling models $[18,19]$, and considering our current findings, we have

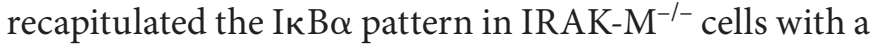
computational model (fig. 8). Intriguingly, our modeling work also projects that other critical downstream negative regulators (such as phosphatases) may be necessary for the proper regulation of IKK activity. Limited work has been done on the contribution of phosphatases to the regulation of the NFKB network. For example, PP2A was shown to dephosphorylate IKKs in addition to p65 [20]. Future studies are warranted to explore the function of relevant phosphatases in the regulation of the complex NFкB network.

The mechanism for IRAK-M-mediated NIK regulation remains unresolved. Previous reports indicate that NIK is extremely unstable and is barely detectable in wildtype cells $[21,22]$. The perturbation of TRAF molecules such as TRAF3 renders NIK stable and active [21,23]. It is therefore likely that IRAK-M may be involved in the regulation of TRAF3 function, and should be tested in the future. The downstream function of NIK also remains less clearly defined. Besides p100 cleavage, recent studies indicate that there are other targets of NIK including IKK $\alpha$ and p65RelA $[24,25]$. Depending upon the nature of stimulants, NIK may activate distinct downstream molecular targets contributing to the $\mathrm{NF} \kappa \mathrm{B}$ activation. Indeed, we found that IKK $\alpha$ phosphorylation was significantly elevated in IRAK-M cells following TLR2 agonist challenge. In contrast, even though we did observe p100 processing and elevated p52 levels in IRAK-M cells, the absolute levels were relatively low. This may be due to the fact that TLR2 agonist is not the optimum stimulant for the activation of NIK-mediated p100 processing. Instead, TLR2 agonist-induced NIK activation may selectively activate other molecular events, such as IKK $\alpha$ phosphorylation, which then lead to elevated RelB transcription and protein levels. The cross talk between NIK and various downstream signaling components within the NFкB network requires extensive future studies.
Although IRAK-M may play a pivotal role in preventing excessive activation of the NFкB network and subsequent inflammatory response, such mechanism may also be exploited by tumor cells or bacteria to evade active immune surveillance. The sepsis syndrome is initiated by dissemination of bacteria or bacterial products (endotoxin) in the blood circulation [26]. The host develops an endotoxin-tolerant state in which blood leukocytes can no longer exhibit inducible NFкB activation and expression of selected inflammatory cytokines, such as TNF $\alpha$ and IL-6 [27]. Suppressed expression of inflammatory cytokines places the host in danger of secondary infections. The suppressed state is caused by deactivation of the innate immunity signaling process, including elevated IRAK-M protein levels in blood leukocytes [28-31]. Analogously, deactivation of innate immunity may also tolerate tumor growth and progression. For example, through a yet-to-be-determined mechanism, tumor-associated macrophages fail to express proinflammatory cytokines, such as IL12p40 and TNF $\alpha$, and not only tolerate, but also facilitate tumor growth [32-34]. A recent study indicates that deactivated macrophages incubated with tumor cells exhibit increased IRAK-M protein levels [35]. Given the evidence indicating the role of IRAK-M in deactivating innate immunity signaling, we hypothesize that cancer cells may exploit the inhibitory function of IRAK-M to evade host immune surveillance. Indeed, our recent study indicates that IRAK-M disruption contributes to enhanced tumor rejection [36]. Our current report provides a mechanistic explanation that the elevation in the alternative NFKB pathway, caused by IRAK-M deficiency, may contribute to enhanced host tumor surveillance.

In summary, we have defined a novel mechanism for IRAK-M-mediated suppression of the NFкB signaling network. Furthermore, our work also reveals intriguing new questions and hypotheses regarding the delicate regulation of this important signaling process.

\section{Acknowledgment}

This study is supported by a grant from the National Institute of Health. 


\section{References}

1 Sen R, Baltimore D: Multiple nuclear factors interact with the immunoglobulin enhancer sequences. Cell 1986;46:705-716.

$\checkmark 2$ Chen LF, Greene WC: Shaping the nuclear action of NF- $\mathrm{B}$. Nat Rev Mol Cell Biol 2004; 5:392-401.

-3 Viatour P, Merville MP, Bours V, Chariot A: Phosphorylation of NF- $\mathrm{B}$ and IкB proteins: implications in cancer and inflammation. Trends Biochem Sci 2005;30:43-52.

4 Dunne A, O'Neill LA: The interleukin-1 receptor/Toll-like receptor superfamily: signal transduction during inflammation and host defense. Sci STKE 2003:re3.

5 Hacker H, Karin M: Regulation and function of IKK and IKK-related kinases. Sci STKE 2006:re13.

6 Dejardin E: The alternative NF- $\kappa$ B pathway from biochemistry to biology: pitfalls and promises for future drug development. Biochem Pharmacol 2006;72:1161-1179.

7 Wesche H, Gao X, Li X, Kirschning CJ, Stark GR, Cao Z: IRAK-M is a novel member of the Pelle/interleukin-1 receptor-associated kinase (IRAK) family. J Biol Chem 1999;274 19403-19410.

-8 Kobayashi K, Hernandez LD, Galan JE, Janeway CA Jr, Medzhitov R, Flavell RA: IRAK$\mathrm{M}$ is a negative regulator of Toll-like receptor signaling. Cell 2002;110:191-202.

$9 \mathrm{Su}$ J, Xie Q, Wilson I, Li L: Differential regulation and role of interleukin-1 receptor associated kinase- $\mathrm{M}$ in innate immunity signaling. Cell Signal 2007;19:1596-1601.

10 Li H, Cuartas E, Cui W, Choi Y, Crawford TD, Ke HZ, Kobayashi KS, Flavell RA, Vignery A: IL-1 receptor-associated kinase $\mathrm{M}$ is a central regulator of osteoclast differentiation and activation. J Exp Med 2005;201: 1169-1177.

11 Balaci L, Spada MC, Olla N, Sole G, Loddo L, Anedda F, Naitza S, Zuncheddu MA, Maschio A, Altea D, Uda M, Pilia S, Sanna S, Masala M, Crisponi L, Fattori M, Devoto M, Doratiotto S, Rassu S, Mereu S, Giua E, Cadeddu NG, Atzeni R, Pelosi U, Corrias A, Perra R, Torrazza PL, Pirina P, Ginesu F, Marcias S, Schintu MG, Giacco GS, Manconi PE, Malerba G, Bisognin A, Trabetti E, Boner A, Pescollderungg L, Pignatti PF, Schlessinger D, Cao A, Pilia G: IRAK-M is involved in the pathogenesis of early-onset persistent asthma. Am J Hum Genet 2007;80:1103-1114.
12 Su J, Richter K, Zhang C, Gu Q, Li L: Differential regulation of interleukin-1 receptor associated kinase 1 (IRAK1) splice variants. Mol Immunol 2007;44:900-905.

13 Huang Y, Li T, Sane DC, Li L: IRAK1 serves as a novel regulator essential for lipopolysaccharide-induced interleukin-10 gene expression. J Biol Chem 2004;279:51697-51703.

14 Xiao G, Harhaj EW, Sun S-C: NF-кB-inducing kinase regulates the processing of NFкB2 p100. Mol Cell 2001;7:401-409.

15 Oganesyan G, Saha SK, Guo B, He JQ, Shahangian A, Zarnegar B, Perry A, Cheng G: Critical role of TRAF3 in the Toll-like receptor-dependent and -independent antiviral response. Nature 2006;439:208-211.

16 Hayden MS, Ghosh S: Signaling to NF-кB. Genes Dev 2004;18:2195-2224.

17 O'Neill LA: The interleukin-1 receptor/Tolllike receptor superfamily: signal transduction during inflammation and host defense. Sci STKE 2000:RE1.

18 Covert MW, Leung TH, Gaston JE, Baltimore D: Achieving stability of lipopolysaccharide-induced NF- $\kappa \mathrm{B}$ activation. Science 2005;309:1854-1857.

19 Kearns JD, Basak S, Werner SL, Huang CS, Hoffmann $A$ : I $\mathrm{B} \varepsilon$ provides negative feedback to control NF- $\mathrm{KB}$ oscillations, signaling dynamics, and inflammatory gene expression. J Cell Biol 2006;173:659-664.

20 Donn RP, Ray DW: Macrophage migration inhibitory factor: molecular, cellular and genetic aspects of a key neuroendocrine molecule. J Endocrinol 2004;182:1-9.

21 He JQ, Saha SK, Kang JR, Zarnegar B, Cheng $\mathrm{G}$ : Specificity of TRAF3 in its negative regulation of the noncanonical NF-kappa B pathway. J Biol Chem 2007;282:3688-3694.

22 Qing G, Qu Z, Xiao G: Stabilization of basally translated NF- $\mathrm{KB}$-inducing kinase (NIK) protein functions as a molecular switch of processing of NF- $\kappa$ B2 p100. J Biol Chem 2005;280:40578-40582.

23 Zarnegar B, Yamazaki S, He JQ, Cheng G: Control of canonical NF- $\kappa \mathrm{B}$ activation through the NIK-IKK complex pathway. Proc Natl Acad Sci USA 2008; 105:35033508.

24 Wang RP, Zhang M, Li Y, Diao FC, Chen D, Zhai Z, Shu HB: Differential regulation of IKK $\alpha$-mediated activation of IRF3/7 by NIK. Mol Immunol 2008;45:1926-1934.

25 Choudhary S, Lu M, Cui R, Brasier AR: Involvement of a novel Rac/RhoA guanosine triphosphatase-nuclear factor- $\kappa \mathrm{B}$ inducing kinase signaling pathway mediating angiotensin IIinduced RelA transactivation. Mol Endocrinol 2007;21:2203-2217.
26 Ishii KJ, Akira S: Toll-like receptors and sepsis. Curr Infect Dis Rep 2004;6:361-366.

27 West MA, Heagy W: Endotoxin tolerance: a review. Crit Care Med 2002;30:S64-S73.

$28 \mathrm{Li} \mathrm{L}$, Cousart S, Hu J, McCall CE: Characterization of interleukin-1 receptor-associated kinase in normal and endotoxin-tolerant cells. J Biol Chem 2000;275:23340-23345.

29 Cuschieri J, Bulmus V, Gourlay D, Garcia I, Hoffman A, Stayton P, Maier RV: Modulation of macrophage responsiveness to lipopolysaccharide by IRAK-1 manipulation. Shock 2004;21:182-188.

30 Deng JC, Cheng G, Newstead MW, Zeng X, Kobayashi K, Flavell RA, Standiford TJ: Sepsis-induced suppression of lung innate immunity is mediated by IRAK-M. J Clin Invest 2006;116:2532-2542.

31 Nakayama K, Okugawa S, Yanagimoto S, Kitazawa T, Tsukada K, Kawada M, Kimura S, Hirai K, Takagaki Y, Ota Y: Involvement of IRAK-M in peptidoglycan-induced tolerance in macrophages. J Biol Chem 2004;279: 6629-6634.

32 Mytar B, Woloszyn M, Szatanek R, BajKrzyworzeka M, Siedlar M, Ruggiero I, Wieckiewicz J, Zembala M: Tumor cell-induced deactivation of human monocytes. J Leukoc Biol 2003;74:1094-1101.

33 Gallina G, Dolcetti L, Serafini P, De Santo C, Marigo I, Colombo MP, Basso G, Brombacher F, Borrello I, Zanovello P, Bicciato S, Bronte V: Tumors induce a subset of inflammatory monocytes with immunosuppressive activity on CD8+ T cells. J Clin Invest 2006; 116:2777-2790

34 Dirkx AE, Oude Egbrink MG, Wagstaff J, Griffioen AW: Monocyte/macrophage infiltration in tumors: modulators of angiogenesis. J Leukoc Biol 2006;80:1183-1196.

35 del Fresno C, Otero K, Gomez-Garcia L, Gonzalez-Leon MC, Soler-Ranger L, Fuentes-Prior P, Escoll P, Baos R, Caveda L, Garcia F, Arnalich F, Lopez-Collazo E: Tumor cells deactivate human monocytes by upregulating IL-1 receptor associated kinase$\mathrm{M}$ expression via CD44 and TLR4. J Immunol 2005; 174:3032-3040.

36 Xie Q, Gan L, Wang J, Wilson I, Li L: Loss of the innate immunity negative regulator IRAK-M leads to enhanced host immune defense against tumor growth. Mol Immunol 2007;44:3453-3461. 